\title{
Correction to: Differing X-ray patterns in seronegative and seropositive rheumatoid arthritis
}

\author{
Ottar Gadeholt ${ }^{1,2}(\mathbb{D}) \cdot$ Katharina Hausotter $^{3} \cdot$ Hannes Eberle ${ }^{4} \cdot$ Thorsten Klink $^{3} \cdot$ Alexander Pfeil $^{5,6}$
}

Published online: 26 July 2019

(C) International League of Associations for Rheumatology (ILAR) 2019

\section{Correction to: Clinical Rheumatology https://doi.org/10.1007/s10067-019-04602-5}

The original version of this article, unfortunately, contained an error.

The first and family names of the authors were interchanged and are now presented correctly. The original article has been corrected.

Publisher's note Springer Nature remains neutral with regard to jurisdictional claims in published maps and institutional affiliations.

The online version of the original article can be found at https://doi.org/ 10.1007/s10067-019-04602-5

Ottar Gadeholt

o.gadeholt@ rheuma-wuerzburg.de

1 Department of Rheumatology, University Clinic Wuerzburg, Wuerzburg, Germany

2 Rheumatologische Schwerpunktpraxis Wuerzburg, Haugerpfarrgasse 7, 97070 Wuerzburg, Germany

3 Department of Clinical and Experimental Radiology, University Clinic Wuerzburg, Wuerzburg, Germany

4 Department of Internal Medicine, Klinikum Esslingen, Esslingen, Germany

5 Department of Internal Medicine III, Jena University Hospital, Jena, Germany

6 Department of Rheumatology, University Clinic Jena, Jena, Germany 